\title{
Cuadro de Clasificación del Archivo del Seminario Metropolitano San Atón de Badajoz: análisis de sus secciones y series documentales
}

\author{
Agustín ViVAs MoReno \\ Universidad de Extremadura \\ avivas@alcazaba.unex.es \\ Francisco GoNZÁLEZ LOZANO \\ fglozano@hotmail.com \\ Guadalupe PÉREz ORTIZ \\ mgperort@alcazaba.unex.es \\ Seminario Metropolitano San Atón de Badajoz
}

Recibido: Diciembre 2014

Aceptado: Febrero 2015

\begin{abstract}
Resumen: Los archivos de seminarios son grandes desconocidos en el panorama archivístico general. En ellos se da custodia a documentación de suma importancia para el desarrollo de estas entidades que tuvieron gran repercusión desde su creación en el Concilio de Trento en el panorama educativo español. El archivo del Seminario Metropolitano San Atón de Badajoz es fiel reflejo de ello, custodiando una interesante documentación que se remonta hasta el siglo XVy que permite el conocimiento pormenorizado de la entidad. En este trabajo pretendemos conocer brevemente la historia de su archivo para adentrarnos en el análisis exhaustivo de su cuadro de clasificación (secciones y series documentales) que nos permitirá por una parte, conocer a la entidad generadora y receptora de documentos y por otra, establecer líneas de clasificación aplicables a otros archivos de seminarios; bajo nuestro punto de vista, cuestión sumamente necesaria en el panorama archivístico eclesiástico.
\end{abstract}

Palabras clave: Archivo seminarios; Archivo Seminario Metropolitano San Atón de Badajoz; Cuadro de clasificación; Secciones y series documentales.

\section{File Classification Table of Metropolitan Seminary St. Aton of Badajoz: analysis of its sections and documentary series}

\begin{abstract}
Files seminars are great unknown in the archival world. Files seminars guard very important documentation, especially since the Council of Trent in education. The file Metropolitan Seminary San Aton of Badajoz custody documentation from the XV century. The study documentation allows us to know the entity. In this paper, we learn the history of your file to get into the comprehensive analysis of your classification scheme. The classification will allow us to meet the generating entity and receiving documents and establish lines of classification applicable to other files seminars. Establish models for other files seminars is a very important task.
\end{abstract}

Keywords: Classification; File Metropolitan Seminary St. Aton Badajoz; Sections; Seminars files. 


\section{INTRODUCCIÓN}

Los archivos eclesiásticos registran el camino seguido a lo largo de los siglos por la Iglesia en cada una de las realidades que la componen. Ya que los archivos eclesiásticos son los lugares de la memoria de la Iglesia, deben recoger sistemáticamente los datos con los que se ha escrito la historia de la comunidad eclesial, para que ofrezca la posibilidad de una atenta valoración de lo que se ha realizado, de los resultados obtenidos, de las omisiones y de los errores.

Conocidos es por todos la labor realizada por la Iglesia en sus veinte siglos de trayectoria. Su finalidad se asentaba en el mandato de Jesucristo a sus Apóstoles de "id y enseñad a todos los pueblos" el evangelio. El paso de los siglos reclamó la creación de una nueva institución que reglara adecuadamente la formación de aquéllos que estaban al frente de las iglesias particulares, los sacerdotes. Basándose en las experiencias de siglos anteriores, el Concilio de Trento ordenó la creación de los seminarios conciliares como centros eclesiales educativos destinados a tal fin.

El presente trabajo centra su atención en el Seminario Conciliar de San Atón de Badajoz, una entidad que se remonta a mediados del siglo XVII. Su trayectoria educativa ha sido un referente en la cultura extremeña. Su prestigiosa influencia formativa, humanística y religiosa ha dejado una huella indeleble en la sociedad a la que sirvió como institución educativa eclesial.

Asentadas estas puntualizaciones, nuestro principal objetivo para el presente estudio es la confección de un hipotético cuadro de clasificación del fondo del Archivo del Seminario Metropolitano San Atón de Badajoz. Para ello deberíamos acometer una serie de actuaciones claves: En primer lugar, el estudio de la institución, es decir, el Seminario, dado que sólo tras un conocimiento del mismo podremos llevar a cabo una clasificación de la documentación emanada en el ejercicio de sus múltiples funciones, actividades y procedimientos administrativos. Este hecho nos permitirá, en segundo término, la realización de un hipotético cuadro de clasificación que se caracterice por su precisión, delimitación, estabilidad, objetividad, simpleza, flexibilidad y eficacia, como herramienta fundamental que permita otorgar una clasificación al fondo documental del Seminario. Además, otro de los objetivos de este trabajo, es exponer someramente los principales contenidos históricos que se pueden extraer de la documentación para dar a conocer posibles líneas de investigación en el archivo a nuestros usuarios y a la comunidad científica en general.

Para alcanzar los objetivos marcados se han empleado diferentes recursos metodológicos, que han dado lugar a una serie de resultados:

Técnicas archivísticas. Dichas técnicas se basaron en el análisis exhaustivo de cada una de las piezas documentales (documentos sueltos) y las unidades archivísticas (expedientes). De la aplicación del método archivístico resulta un fondo documental que presenta una disposición organicista donde cada uno de los 
documentos sólo tiene sentido en relación con los demás, y preparado para ser consultado por el usuario.

Análisis histórico. Para su procedimiento se ha examinado la documentación del archivo desde el punto de vista del investigador interesado en la historia. El resultado ha mostrado las características generales e históricas de la documentación, siendo enmarcadas en el contexto sociocultural e interpretadas históricamente.

\section{EL NACIMIENTO DE LOS SEMINARIOS: APROXIMACIÓN AL SEMINARIO METROPOLITANO SAN ATÓN DE BADAJOZ Y A LA CONSTITUCIÓN DE SU ARCHIVO}

Los archivos eclesiásticos registran el camino seguido a lo largo de los siglos por la Iglesia católica en cada una de las realidades que la componen. Ya que son los lugares de la memoria de la Iglesia, deben recoger sistemáticamente todos los datos con los que se ha escrito la historia de la comunidad eclesial, para que ofrezcan la posibilidad de una atenta valoración de lo que se ha realizado, de los resultados obtenidos, de las omisiones y de los errores (Asociación de Archiveros de la Iglesia en España, 1997).

Prácticamente desde sus orígenes, la Iglesia ha intentado conservar los documentos por ella generados. En un primer momento, el objetivo no era otro que el de intemporalizar la doctrina. Posteriormente fueron los archiveros eclesiásticos los encargados de organizar y describir la documentación en sus archivos conservada. Al tratarse la Iglesia católica de una institución privada, el acceso a sus archivos es restringido. En contraposición, en ellos se custodia documentación de gran valor y antigüedad. No debemos obviar las vicisitudes acaecidas por la Iglesia, algunas de ellas ocasionaron pérdidas de incalculable valor patrimonial. Aún a pesar de ello nuestras parroquias, catedrales, monasterios, conventos y seminarios han sabido conservar un legado documental de infinito valor histórico.

En los primeros siglos de la Iglesia, los obispos recorrían sus diócesis en busca de jóvenes que estuvieran al servicio del Pueblo de Dios. Cómo fue y se llevó a cabo su formación no nos consta detalladamente. A partir del siglo II surgen las escuelas catequéticas, que encontrarán, a partir del 313, su organización definitiva. Los concilios de Nicea (325), Constantinopla (381), Éfeso (431) y Calcedonia (451) sustentarán esta formación. Dichas escuelas catequéticas estarán vigentes hasta el siglo V.

La caída del Imperio romano y la situación de la Iglesia como única fuente sólida de principios morales y religiosos fue dando paso a la creación de escuelas catedralicias. El concilio II de Toledo (527) hacía hincapié en la dimensión formativa seria y el carácter diocesano de estas escuelas episcopales. Empezamos a encontrar antecedentes muy similares a los actuales seminarios durante los siglos posteriores; así, en el concilio I de Aquisgran, celebrado en el 816, ya encontramos 
las líneas directrices de estas futuras instituciones. Tras la reforma cluniacense florecen las escuelas catedralicias. El III Concilio de Letrán dispuso en 1119 que en todas las catedrales existiera la figura del maestrescuela (Brown, 1990: 230-303).

El nacimiento de una nueva institución orientada a la formación de los clérigos nos conduce directamente a la situación de la Iglesia católica en un periodo de confusión doctrinal provocada por las teorías de Lutero, Calvino y Zwinglio. La teología católica comenzaba a resquebrajarse, por lo que fue necesario un impulso a la formación sacerdotal.

Así pues, los seminarios nacieron a raíz del Concilio de Trento (1545-1563) como centros para atender la formación del clero que en el siglo XVI era un tanto escasa. En concreto en la sesión XXIII del Concilio, que se desarrolló desde el 15 de julio de 1563 al 11 de noviembre de 1563, se aborda, junto con la doctrina sobre el Sacramento del Orden, la creación de seminarios para los clérigos y se dispone que las catedrales fueran las que se encargaran de su fundación y consolidación (Concilium, 1901: 628-630).

Las reflexiones del Concilio nos acercan a un clero frágil intelectualmente. De esta manera se decreta la creación y la obligatoriedad de los seminarios sacerdotales en las diócesis, lo cual es confirmado por el Papa Pío IV (Rops, 1970: 104-ss.). Durante la segunda mitad del siglo XVI y hasta finales del siglo XVII, la aplicación del decreto conciliar fue urgida por Sínodos particulares, obispos y sacerdotes. A pesar de ello, en la diócesis de Badajoz, al igual que en las otras diócesis extremeñas, los sínodos celebrados antes de Trento muestran ya la preocupación por la instrucción de los clérigos, como consta en el de 1501 (García, 1990).

La primera mitad del siglo XVIII se caracteriza por asentar las bases de una reforma en el seno de la Iglesia que se consolidará durante el reinado de Carlos III y Carlos IV y que afectará, sin igual, a los seminarios. Si la Iglesia española, ha conocido momentos de renovación, quizás los que acontecieron en el siglo XVIII fueron los más significativos, especialmente si miramos al seminario, cuando a medio hacer la universidad moderna, y diluidos los colegios universitarios, éstos llegan a ser epicentro de la vida educativa. Mientras en España se iban desarrollando variados sucesos, como la expulsión de los Jesuitas, el monarca Carlos III emite una Real Cédula, el 14 de agosto de 1768, para regular y reformar los seminarios. Con Carlos IV, se pretende continuar con la dinámica iniciada con su antecesor. A pesar de todo, había llegado ya la decadencia de estas instituciones. Durante la primera mitad del siglo XIX la acción combinada de los obispos y del Estado hizo que la renovación fuera posible (Martín Hernández, 1959: 357-358).

El tiempo y los estudios históricos constatan que la creación de los seminarios no fue un hecho inmediato a la promulgación de los decretos tridentinos. Una de las razones por las que se retrasó el inicio de estas instituciones fue la coexistencia con colegios y universidades. La universidad española gozaba de gran prestigio y entorno a ella surgieron estos centros universitarios que hicieron las veces de seminarios (Blanco Cotano, 1998: 21-22). Otras razones que impidieron la 
inmediata fundación de los seminarios fueron la pobreza de las diócesis y la resistencia de algunos cabildos catedralicios que habían llevado la dirección de las escuelas catedralicias que antaño cumplieron funciones formativas (Pérez Ortiz; González Lozano, 2014: 49-53).

En el caso particular de Badajoz se observa la preocupación por la instrucción de los clérigos y los diferentes modos de establecerla. La ciudad se ve inmersa en esta situación durante un largo periodo. Por ello, el rey Felipe II tuvo que recordar a nuestro cabildo, en 1594, que habían pasado más de treinta años desde la celebración del Concilio y que no se había hecho nada al respecto. Veamos literalmente sus palabras:

Avía mas de treinta / años que el concilio se avía publicado y esta obra..., tan neçesaria y conveniente / para todo el Reyno por la utilidad que resultaría de que los niños se criasen en / buena doctrina y costumbres y letras, no se avía executado ni cumplido", por lo que ruega y encarga a la corporación capitular "que dentro de veinte días primeros siguientes después / que os fuera mostrada -la carta- enviéis ante los del nuestro consejo relación, en manera que / haga fee, si en esse obispado se a hecho el dicho seminario por la orden que por el / sanctoconçilio se dispone y quánto a que se hiço y qué renta se le applicó

(A.C.B. Cartas Reales, Tomo $1^{\circ}, \mathrm{n}^{\circ} 20$ ).

La escasez de beneficios y rentas obligaron al cabildo pacense a dilatar en el tiempo la creación de nuestro seminario. Para la puesta en marcha del mismo serán de suma importancia los legados y mandas pías que se constituyeron. La más importante, sin lugar a dudas, la obra pía del canónigo Rodrigo Dosma. Lo pone de manifiesto su testamento, otorgado el 8 de mayo de 1588, en el que sus bienes quedaban vinculados a favor de la descendencia que tuviera su hermano, siguiendo como beneficiarios los sucesores de la misma; pero, faltando tal descendencia y sucesores, las dos terceras partes de tales bienes pasarían al que fuera "seminario que se erija en las casas grandes de mi morada” y si tal seminario hubiera sido erigido antes de que tales bienes quedaran desvinculados era voluntad de nuestro canónigo que, producido este hecho, pasase de inmediato a sus casas. Tal y como aparece en el libro de Fundación de la entidad, al principio existieron problemas con los herederos directos del canónigo, que tuvo que refrendar el obispo don Jerónimo Rodríguez de Valderas (1662-1668), consiguiendo que el seminario se instaurara en la casa del fallecido canónigo en el año.

Se instituye el Seminario de Badajoz el 26 de Mayo de 1664, siendo obispo de la diócesis de Badajoz, Jerónimo Rodríguez de Valderas, según refleja el título 27 de las Constituciones que se aprobaron para la vida cotidiana del centro (Rubio Merino, 1964: 328), aunque se tiene constancia de que el 3 de mayo ya estaban los primeros colegiales en su interior. 
En el año 1733, se adquieren por el obispado unas casas frente al Palacio Episcopal y en el año 1754 se instalan los colegiales en ellas. Posteriormente, en 1927, adaptándose a las vicisitudes de los nuevos tiempos, el Seminario ocupó un terreno en la Cañada Sancha Brava, ubicación actual de la entidad.

Figura 1. Dependencias actuales del Seminario de Badajoz

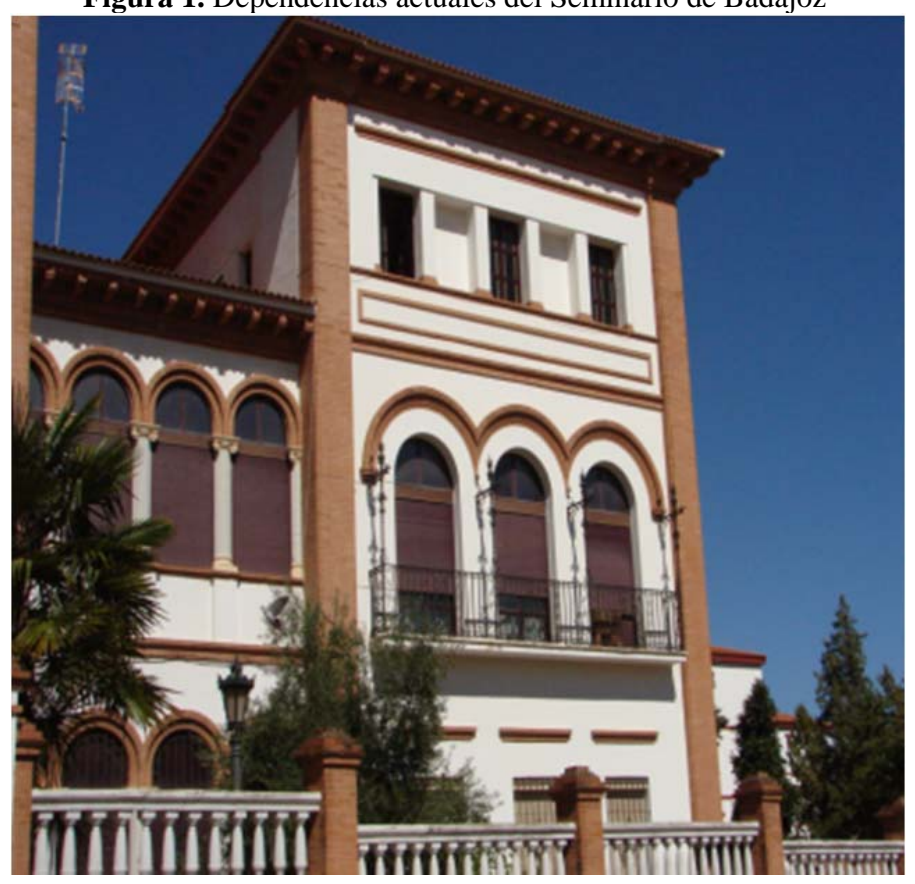

El archivo se crea a la vez que se instituye el Seminario según consta en las Constituciones que se aprobaron para la vida cotidiana del centro, en su Título 27. Veamos unas líneas que así lo demuestran:

En el lugar y parte que para este efecto de ser Archibo, se señalare, se pondrán tres cerraduras y llaves diferentes, las quales se tendrán las mismas personas, que esta dicho han de tener las del Arca: Y en casso que qualquiera de ellas enfermare o hiciere ausencia del Colegio entregará unas y otras en presencia de la Capilla al que le hubiere de suceder en el oficio.

En el dicho Archibo se han de guardar todos los papeles pertenecientes a la fundación y erección del Colegio; los Titulos de las Uniones y agregaciones de los Beneficios Simples y los de qualesquiera otra hacienda y Vienes que finalmente todos los papeles necesarios para guarda del derecho del Colegio. Y anssimesmo se pondrán las quentas 
que el Prelado tomare de la Hacienda del Colegio con todos los recaudos, para su verificación se presentaron.

Y tendrasse un libro dentro del dicho Archibo en que aya razón de todos los Papeles que en el hubiere y de los que se sacaren con dia, mes y año y firma del que los recibiere para que le vuelva o de razón del.

Ha de haver otro libro en que se escriban las entradas de Rectores y Colegiales, y de cómo juraron con día, mes y año y los traslados de las probissiones que pressentaren. En otro libro se escriban las ausencias que el Rector y Colegiales hicieren, y con qué licencia, por quanto tiempo, y ansi mismo se escriba el día que bolbieron.

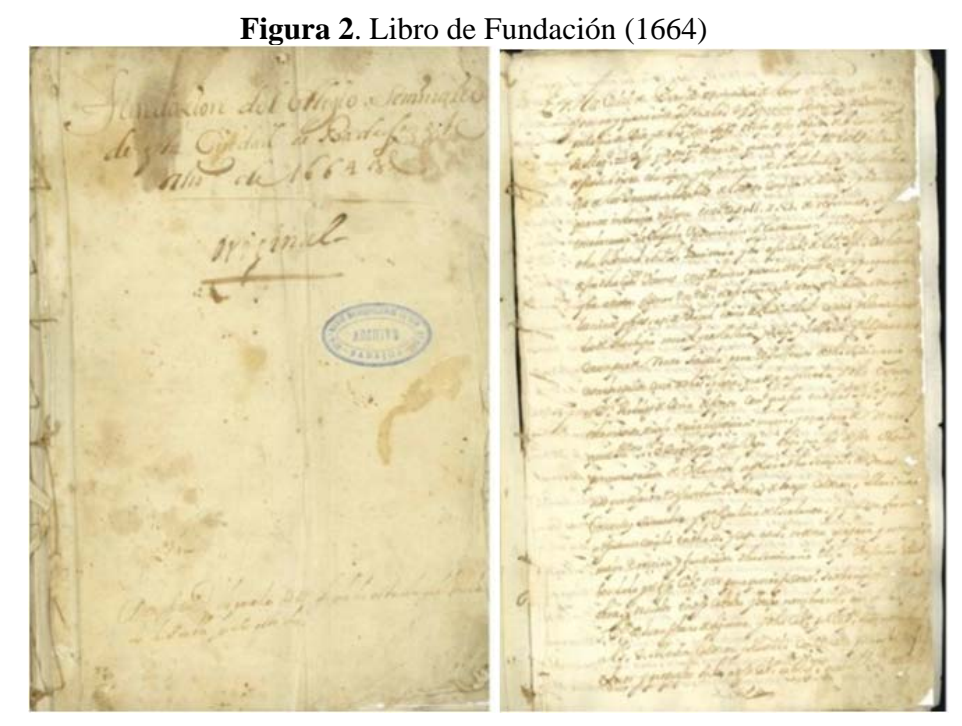

El archivo, por tanto, contiene la documentación producida y recibida por la entidad en el trascurso de su actividad educativa, litúrgica, pastoral y la derivada de la conservación y gestión de supatrimonio; así como la de otras instituciones (colegios-seminarios) dependientes de él, todas hoy desaparecidas.

La creación del Seminario supuso una ingente producción de documentos. En líneas generales el fondo histórico, con un total de 140 libros y 131 cajas, del archivo del Seminario se distribuye de la siguiente forma:

$>$ Fondo del Seminario Diocesano de San Atón.

$>$ Fondo del Colegio-Seminario de San Benito en Villanueva de la Serena.

$>$ Fondo del Colegio-Seminario Nuestra Señora de la Coronada en Villafranca de los Barros.

$>$ Fondo de los Seminarios de Elvas y Olivenza.

$>$ Fondo Musical. 
$>$ Fondo Colecciones.

En un primer momento la documentación del archivo se encontraba dispuesta en legajos que fueron debidamente adaptados en cajas archivadoras para su mejor conservación y custodia. Una vez revisados los legajos, la documentación fue cotejada con un catálogo descriptivo previo, confeccionado por el canónigo archivero Pedro Rubio Merino, que estaba realizado conforme a las Constituciones de 1664 y 1783, respectivamente y al Reglamento de 1863. En base a ello se confeccionó un cuadro de clasificación, adaptándolo a la Norma ISAD (G), que permite respetar la ordenación establecida anteriormente.

Se presenta este cuadro dividido en tres grandes secciones, de acuerdo a las Constituciones del centro y al Reglamento interno; así como a la propia reglamentación canónica. Además, se añade una cuarta sección que es la que se dedica a la documentación conservada de los colegios dependientes (San Benito, La Coronado, Elvas/Olivenza); la quinta al fondo musical y la sexta y última a los fondos colecciones: fotografías y monedas.

\section{CUADRO DE CLASIFICACIÓN DEL ARCHIVO DEL SEMINARIO METROPOLITANO SAN ATÓN DE BADAJOZ}

Presentamos a continuación el cuadro de clasificación diseñado para el archivo del Seminario san Atón de Badajoz, así como de los fondos dependientes en él custodiados.

Realizar un instrumento descriptivo no ha sido una tarea sencilla. Varias son las problemáticas que nos hemos encontrado y que conviene identificar previamente:

- Largo periodo de desarrollo de la institución generadora. Este hecho dificulta las tareas clasificatorias, puesto que al encontrar documentación de épocas dispares es más complejo agruparlas bajo principios heterogéneos.

- La complejidad de la institución. Sufrió modificaciones estructurales que dificultan una clasificación organicista.

- La escasa bibliográfica publicada. No existen apenas estudios que analicen en profundidad las principales tipologías documentales que encontramos en archivos de seminarios (Vivas Moreno; González Lozano; Pérez Ortiz, 2015; 105-125; González Lozano; Pérez Ortiz, 2014: 9-24) relegando estos contenidos a obras generales donde aparecen apartados, más o menos extensos, sobre el patrimonio cultural de estas entidades (Blanco Cotano, 1998; García Hernando, 1959; Hernández Corrales, 1992; Hernández Figueiredo, 1992; Martínez Campos, 2013; Rubio Merino, 1964).

En el caso específico del Seminario Metropolitano de Badajoz, encontramos obras generales de marcado carácter histórico (Blanco Cotano, 1998; Rubio Merino, 1964; Solar y Taboada, 1945), aunque bien es cierto que desde la 
entidad se viene realizando, en los últimos tiempos, un esfuerzo loable por dar a conocer la documentación custodiada en su archivo (Fuentes Nogales; Pérez Ortiz, 2014: 323-372; Id., 2014; Vivas Moreno; González Lozano; Pérez Ortiz, 2015; 105-125; González Lozano; Pérez Ortiz, 2014: 9-24) que se está viendo plasmado en diversas publicaciones.

En base a ello, se ha pretendido con la confección de esta herramienta documental el establecimiento de un instrumento descriptivo de carácter simplista que atienda a lo múltiple y heterogéneo de la documentación y a los fondos que sirve. Veamos el cuadro diseñado:

\section{CUADRO DE CLASIFICACIÓN PARA EL ARCHIVO DEL SEMINARIO METROPOLITANO SAN ATÓN DE BADAJOZ}

\subsection{GOBIERNO}

1.01 Documentación Episcopal
1.01.01 Bulas
1.01.02 Constituciones
1.01.03 Libro Actas de Visita
1.01.04 Libro Decretos Episcopales
1.01.05 Libro Doc. Obispo y Obispado
1.01.06 Libro Fundación Seminario
1.01.07 Libro Inventario Obispado
1.01.08 Reglamentos

1.02 Documentación Rectorado

1.02.01 Actas Seminario

1.02.02 Libro de Actas Académicas

2.0 SECRETARÍA

2.01 Asuntos Académicos

2.01.01 Actas de Exámenes

2.01.02 Becas

2.01.03 Expedientes de Conducta

2.01.04 Listado de Alumnos

2.01.05 Matrículas

2.01.06 Solicitud/Justificantes

2.02 Asuntos Generales

2.02.01 Cédulas Reales

2.02.02 Certificaciones

2.02.03 Correspondencia 
Agustín Vivas, Francisco González, Guadalupe Pérez Cuadro de Clasificación del Archivo del...

2.02.04 Expedientes Personales

2.02.05 Informaciones

2.02.06 Planes de Estudios

3.0 ADMINISTRACIÓN

3.01 Administración General

3.01.01 Correspondencia

3.01.02 Cuentas

3.01.03 Obras

3.01.04 Pagos

3.01.05 Recibos/Justificantes

3.01.06 Salarios

3.02 Bienes

3.02.01 Censos

3.02.02 Cuentas

3.02.03 Escrituras

3.02.04 Inventario de Bienes

3.02.05 Libro Becerro

3.03 Obras Pías

3.03.01 Administración

- Cuentas

- Inventario de Bienes

- $\quad$ Libro de Cuentas

3.03.02 Obras Pías

- Arias de Hoces

- Bravo de Laguna

- Diego Hernández

- $\quad$ Duque de Bejar

- Feria

- Fonseca

- Francisco López Chávez

- Francisco Mejías

- Josefa Vicente Rino

- Marques de Lapilla

- Pedro Casas Guerrero

- Rodrigo Dosma

- Somoza Ribera 
4.0 FONDOS COLEGIOS-SEMINARIOS DEPENDIENTES

4.01 Fondo Seminario Menor Elvas-Olivenza

4.01.01 Censos

4.01.02 Correspondencia

4.01.03 Cuentas

4.01.04 Foro de Trigo

4.01.05 Informes

4.02 Fondo Seminario Menor de Nuestra Señora de la Coronada. Villafranca de los Barros
4.02.01 Cuentas
4.02.02 Notas

4.03 Fondo Seminario Menor de San Benito. Villanueva de la Serena
4.03.01. Cuentas
4.03.02 Escrituras
4.03.03 Matrículas
4.03.04 Notas
4.03.05 Solicitudes

5.0 FONDO MUSICAL

5.01 Música sacra

5.02 Música profana

6.0 FONDO COLECCIONES

6.01. Fotografías

6.02 Monedas

\section{ANÁLISIS DE LAS PRINCIPALES SECCIONES Y SERIES DEL CUADRO DE CLASIFICACIÓN DEL ARCHIVO DEL SEMINARIO METROPOLITANO SAN ATÓN DE BADAJOZ}

Es momento de ir desgranado este cuadro de clasificación del archivo del Seminario de san Atón de Badajoz para ir conociendo la documentación conservada. Como es lógico desarrollará una estructura vertebradora similar al resto de los cuadros de clasificación diseñados para archivos de seminarios ${ }^{1}$ que

\footnotetext{
${ }^{1}$ Para el desarrollo del cuadro de clasificación del Archivo del Seminario de Badajoz han sido tomados como referencia el cuadro propuesto por el canónigo archivero Pedro Rubio Merino (1999), en su manual: Archivística Eclesiástica: Nociones básicas. Sevilla, Guadalquivir; así como las directrices que marca la Asociación de Archiveros de la Iglesia
} 
encontramos en los escasos trabajos previos $\mathrm{y}$ fundamentalmente en recomendaciones o pautas de actuación que se vienen desarrollando por la Asociación de Archiveros de la Iglesia en España.

GOBIERNO 1.0: la primera de las secciones del cuadro de clasificación abarca la documentación que ha generado el Seminario en su autogobierno. Se establecen dos grandes subsecciones: una dedicada al obispo y otra al rector. Veamos cada una de ellas:

Documentación episcopal (1.01): da cabida a la documentación generada por el obispo, cuyo receptorprincipal era el Seminario. El obispo como cabeza de la Iglesia local tenía una relación fluida con el Seminario como dan prueba los documentos conservados en su archivo. Su misión principal era el adoctrinamiento de los seminaristas para lo que mantiene continúas comunicaciones. Las series documentales principales son:

Bulas 1.01.01: en el archivo del Seminario se conservan varias bulas de los siglos XVII y XVIIIcuya misión principal era llevar el adoctrinamiento papal a los seminarios, en concreto esta documentación hace referencia directa al de Badajoz.

Constituciones 1.01.02: eran las leyes fundamentales por las que se regía el Seminario de San Atón. Como es lógico debieron existir diferentes constituciones que corresponderían fundamentalmente a los obispos que rigieron la diócesis. En el archivo se custodian las de 1783-1797, del obispo Solís y Gragera, y las de 1849, del obispo Rodríguez Obregón. Su análisis nos permite observar la evolución estructural del Seminario, así como los cambios sociológicos que también se iban introduciendo.

Libro actas de visita 1.01.03: es el libro en el que los visitadores hacen constar de manera circunstanciada, esto es, detallada, los hechos que conocen durante el desarrollo de la visita al Seminario. Su fecha de datación es de 1900 a 1906 y da debida información de este proceso.

Libro decretos episcopales 1.01.04: como su nombre indica, son los decretos y disposiciones emitidos específicamente por el obispo para ser cumplimentados en el Seminario. Su distribución cronológica es escasa, desde 1867 a 1868, correspondientes al periodo del obispo Fernando Ramírez Vázquez.

Libro documentación obispo y obispado 1.01.05: este libro de 1734, recoge disposiciones específicas del obispo Amador Merino Malaguilla para ser

Español. MARTÍ BONET, J.Ma (coord.) (2001). Guía de los archivos de la Iglesia en España. Barcelona, Asociación de Archiveros de la Iglesia. 
cumplimentadas en el Seminario de Badajoz. Nos permite observar ciertas pautas dictaminadas por el obispo para nuestra entidad.

Libro fundación 1.01.05: es el documento más importante desde el punto de vista histórico custodiado en el archivo del Seminario porque en base a él se erige la institución. Su fecha de datación es de 1664 y recoge punto por punto las disposiciones desarrolladas para la erección del Seminario de Badajoz.

Libro inventario obispado 1.01.07: bajo esta serie documental se dan cabida correspondencia, documentación de beneficiados, capellanías y reliquias relativas al Seminario del año 1734.

Reglamentos 1.01.08: recopilación de disposiciones específicas para regular la actividad cotidiana del Seminario, entre los años 1863 a 1926, que fue dictaminada por el obispo Pantaleón Monserrat. Su análisis pormenorizado nos permite acercarnos al funcionamiento de la entidad y conocer su estructura interna.

Documentación rectorado 1.02: da cabida a la documentación que ha sido generada por los diferentes rectores que han estado al frente del Seminario, tanto en el desarrollo de sus competencias como en su comunicación directa con el obispo y otras instituciones o particulares. Las series fundamentales que la constituyen son:

Actas seminario 1.02.01: son los documentos que recogen los puntos discutidos y acuerdos adoptados en las diferentes reuniones convocadas por el rector y que dan cita a los diferentes miembros que integran el Seminario. En nuestro archivo pueden ser analizadas las actas de 1853 a 1934. Su análisis permite el conocimiento específico de cuestiones relacionadas con la educación en estos centros de enseñanza y a las relaciones con otros centros e instituciones, como el gobierno civil, Diputación, Ayuntamiento, Universidades de Salamanca y Sevilla, Ministerio de Educación...

Libro de actas académicas 1.02.02: en la formación interdisciplinar de los seminaristas se encontraban las "academias", conferencias semanales que, guiadas por el rector y director de estudio, tenían como protagonistas a los propios seminaristas de la etapa filosófica y teológica. Este libro recoge un resumen de estas disertaciones y el modo de llevarlas a cabo entre 1909 y 1918.

SECRETARÍA 2.0: esta sección da cabida a la parte más funcional de los seminarios. Como entidades educativas que son, los seminarios van a hacer una clara distinción entre una secretaría más general, que puede ser extrapolada a cualquier otra entidad o empresa, de una secretaria académica que va a gestionar asuntos específicamente relacionados con la docencia.

Asuntos Académicos 2.01: los seminarios como entidades educativas que son tienen una secretaría específica para las cuestiones puramente académicas. En el caso del Seminario de Badajoz, la documentación que da 
cabida a esta subsección es abundante y muy variada, distribuyéndose cronológicamente desde el siglo XVII al XX. Veamos las principales series documentales que lo constituyen:

Actas de exámenes 2.01.01: son los documentos que recogen ordenadamente los diversos exámenes que se realizaron en este Seminario entre 1858 y 1930.

Becas 2.01.02: los seminarios entendidos como entidades educativas no han obviado nunca a los niños y jóvenes más necesitados. Para ellos se desarrolló un sistema de becas que previos ciertos requisitos (económicos y académicos) permitía a los candidatos el desarrollo de sus estudios en igualdad de condiciones que el resto de alumnos.

El archivo del Seminario de Badajoz da prueba de ello siendo muy abundante la documentación sobre becas en el siglo XIX y XX. Tenemos que entender que esta documentación se refiere exclusivamente a becas porque en los expedientes personales y libros de informaciones de alumnos vamos a hacer alusión a este concepto como parte integrante de un expediente completo.

Expedientes de conducta 2.01.03: son informes específicos elaborados por los párrocos que cada uno de los alumnos del Seminario debían presentar al obispo y al rector para poder ingresar en el mismo. Se da debidamente cuenta de su procedencia y actitudes, así como de su relación con la Iglesia. Este expediente solía formar parte de otro más amplio del candidato, de ello podemos observar que sólo se conservan en nuestro archivo estas fichas de forma aislada de los años 1862 a 1908, sin embargo este documento debe aparecer en todos los expedientes de alumnos que han pasado por el Seminario.

Listado de Alumnos 2.01.04: como su nombre indica, es la relación ordenada de los alumnos del Seminario de San Atón en los diferentes cursos de los que se conserva esta documentación, es decir, de 1853 a 1895. Su análisis nos facilita un valor testimonial y probatorio sobre el paso por este centro de ciertos personajes.

Matrículas 2.01.05: estos registros de alumnos que cursaron sus estudios en el Seminario de Badajoz son muy frecuentes en nuestro archivo. La distribución cronológica de la documentación así lo atestigua, permitiendo su estudio desde 1793 a 1930. El análisis de estos registros nos facilitará el desarrollo de estudios relativos a alumnos determinados, procedencias, edades, cronologías de mayor o menor apogeo en Seminario, que pueden relacionarse no sólo con aspectos puramente académicos.

Solicitud/Justificantes 2.01.06: los alumnos que deseaban ingresar en el Seminario debían enviar al obispo una súplica o solicitud informando de los deseos que le llevaban a querer ingresar en este centro. En el archivo se conservan solicitudes aisladas, en la mayoría de casos forman parte de expedientes completos como ya hemos hecho alusión en las fichas de conductas o en las becas, de los años 1868 a 1889. 
Asuntos Generales 2.02: se trata de la secretaría general que da cabida a documentos de variada índole que surgen del funcionamiento diario del propio Seminario. Las principales series documentales que lo integran son:

Cédulas Reales 2.02.01: en el archivo se conserva un libro de Cédulas Reales de 1767 a 1771 del rey Carlos III, en el que se determinan ciertas obligaciones y pautas para ser ejecutadas en el Seminario de Badajoz.

Certificaciones 2.02.02 : se conservan en el archivo un nutrido conjunto de estos documentos desde 1828 a 1904 en el que se da constancia de ciertos procesos de carácter académico en el Seminario. Son usuales en nuestro archivo los certificados de notas.

Correspondencia 2.02.03: conjunto de cartas que se envían y se reciben por el Seminario para una comunicación directa con otras instituciones. En este caso hacemos alusión a la correspondencia puramente académica que se distribuye entre 1806 y 1922.

Expedientes Personales 2.02.04: esta serie documental es una de las más importantes de nuestro archivo, no sólo por su amplísimo volumen (42 cajas), también por su distribución cronológica (1853-1923).

Los expedientes de alumnos junto con los libros de informaciones, que veremos posteriormente, constituyen el eje vertebrador de nuestro archivo. Estos expedientes nos permiten conocer el proceso de entrada en el Seminario de principio a fin. Constan de: solicitud de ingreso, certificado de la partida de bautismo, en algunos casos se incluye el de confirmación, certificado de conducta, certificado médico. También es dentro de estos expedientes donde se hace alusión nuevamente a las becas, dado que muchos alumnos en su solicitud inicial piden no sólo la entrada al Seminario sino también la concesión de la beca.

Hay que entender que el estudio pormenorizado de esta documentación es vital en la historia educativa y pedagógica de la comunidad de Extremadura dado que el Seminario asumió el papel de primera universidad y de primer centro de enseñanzas secundarias (Sánchez Pascua, 1985) durante un periodo significativo de tiempo. Este hecho supondrá que estudios a nivel educativo de los siglos XVIIXVIII deban hacer alusión directa al archivo de san Atón.

Informaciones 2.02.05: esta serie documental junto con los expedientes personales de alumnos es una de las más representativas de nuestro archivo, no sólo por su amplísimo volumen (44 libros), también por su distribución cronológica (1683-1853).

Los libros de informaciones recogen los datos relativos al candidato que quería acceder a nuestro Seminario. Presentan una estructura muy similar a los expedientes de alumnos y serán de gran utilidad para la confección de biográficas específicas sobre personales ilustres que han pasado por nuestras aulas a lo largo de los más de tres siglos de existencia de la entidad.

Planes de Estudios 2.02.06: documentación sobre las enseñanzas organizadas en el Seminario en 1853 para la obtención de la titulación académica correspondiente. 
ADMINISTRACIÓN 3.0: la tercera de las secciones de nuestro cuadro de clasificación está relacionada con las actividades encaminadas a la gestión de los bienes propios del Seminario, así como de los colegios dependientes de él. El encargado principal de la gestión de los citados bienes es el rector que se apoya en un equipo constituido en el propio Seminario. Queda constituida por tres subsecciones:

Administración General 3.01: como su nombre indica, esta subsección va a dar cabida a la documentación administrativa de carácter general que se custodia en el Seminario (actas, cuentas, pagos, correspondencia, etc.). Está integrada de las siguientes series documentales:

Correspondencia3.01.01: conjunto de cartas que se envían y se reciben por el Seminario para una comunicación directa con otras instituciones. Son muy frecuentes las comunicaciones del obispo con la entidad. Abarca el periodo de 1888 a 1917.

Cuentas 3.01.02: documentos puramente contables en los que aparecen los gastos diarios del Seminario desde 1797 a 1922. El análisis de esta amplísima documentación nos permitirá confeccionar un diario de a bordo del funcionamiento de una entidad por la que han pasado miles de niños y jóvenes. Su estudio nos permitirá abordar cuestiones tan variopintas como la economía o aspectos de carácter sociológico y nutricional en la sociedad de los siglos XVIII al XX.

Obras 3.01.03: alberga la documentación relativa a obras realizadas en el Seminario desde 1893 a 1931: planos, certificaciones, bocetos, informes son algunos de los documentos que la integran. No debemos olvidar que al tratarse de construcciones antiguas en las que cohabitan muchas personas las obras se convierten en una situación casi habitual en estas entidades. Su análisis nos permitirá conocer a grandes arquitectos o restauradores que han pasado por san Atón.

Pagos 3.01.04: la vida diaria de una institución en la que habitan gran número de personas genera abundante documentación relativa a esta cuestión en la que quedan reflejados los gastos de la entidad desde 1830 a 1857.

Recibos/Justificantes 3.01.05: se conserva en el archivo una abundantísima documentación relativa a recibos y justificantes desde 1792 a 1932. El análisis de esta documentación puede llevar a los investigadores al estudio de cuestiones muy heterogéneas: economía, alimentación, sanidad, sociología, arte y arquitectura, etc. Debe ser reconocida esta documentación como base para el desarrollo de otros estudios.

Salarios 3.01.06: documentación relativa a los sueldos de los trabajadores del Seminario de san Atón entre 1830 y 1857. Su análisis, además de cuestiones puramente económicas, nos permite trazar el organigrama de la entidad en base a las personas que reciben remuneración o gratificación.

Bienes 3.02: conjunto de documentos referidos a las posesiones de las que el Seminario fue acreedor desde el siglo XVII. En líneas generales los bienes de san Atón estaban integrados por diversas fincas y casas, así como por patrimonio artístico. Las series documentales principales son: 
Censos 3.02.01: dentro de la economía agraria de España las tierras estaban gravadas por una serie de rentas que se llamaban censos. Éstos se pagaban en especie y sirvieron de sustento tanto a la monarquía como a la Iglesia. El Seminario de Badajoz fue destinatario de algunos de ellos, como indica la documentación conservada desde 1464 a 1921, permitiendo el estudio de este procedimiento, muy habitual en épocas pasadas, con un volumen documental ciertamente significativo.

Cuentas 3.02.02: documentación contable desde 1668 a 1850, que dado a su especificidad (exclusiva a bienes) ha sido ubica en esta parte de clasificación.

Escrituras 3.02.03: el archivo custodia un amplio volumen de escrituras tanto de venta, compraventa como de permuta, siendo estas últimas las más representativas por su volumen. Su distribución cronológica es muy amplia, desde el siglo XV, permitiendo además el estudio de un conjunto de escrituras relativas a bienes que el Seminario de Badajoz poseía en la Torre de Miguel Sesmero.

Inventario de Bienes 3.02.04: documentación acreditativa de los diferentes bienes con los que el Seminario de san Atón ha contado a lo largo de su historia. Su distribución cronológica entre los siglos XVI y XVIII nos permite abordar estudios relevancia especialmente relativos a cuestiones artístico-patrimoniales donde encontramos informes detallados de su patrimonio.

Libro Becerro 3.02.05: este libro del siglo XVIII recoge a mano los privilegios del Seminario para uso manual y corriente. Aunque no tienen la relevancia de los libros conservados en monasterios también gozaron los seminarios de ciertos privilegios que les permitieron desarrollar su trayectoria de un modo desahogado.

Obras pías 3.03: documentación relativa a estas fundaciones pías perpetuas que en el caso del Seminario de Badajoz aportan contenidos de suma relevancia para estudios de tipo histórico.

Administración 3.03.01: como su nombre indica es la documentación resultante del funcionamiento y la gestión de capellanías y obras pías en el Seminario. Son sumamente interesantes las cuentas (1779-1910) y los inventarios de bienes (17691866) donde se exponen los diversos elementos asignados a estas mandas pías.

Obras pías 3.03.02: en el Seminario de Badajoz se custodia documentación relativa a trece obras pías, que no eran más que instituciones hechas con autoridad de juez ordinario y fundación de rentas competente con obligación de misas y algunas con asistencia a las horas canónicas.

La documentación es amplísima, al igual que lo es su distribución cronológica desde 1599 a 1885, y permite el estudio pormenorizado de las siguientes obras pías: Arias de Hoces, Bravo de Laguna, Diego Hernández, Duque de Béjar, Feria, Fonseca, Francisco López Chavez, Francisco Mejías, Josefa Vicente Rino, Marqués de la Lapilla, Pedro Casas Guerrero, Rodrigo Dosma (en ella aparece la cesión de sus casas para la consecución del Seminario de Badajoz en 1664), Somoza Ribera. Sin lugar a duda el análisis exhaustivo de esta documentación es vital para cuestiones histórico-patrimoniales de la provincia de Badajoz desde el siglo XV. 
FONDOS COLEGIOS-SEMINARIOS DEPENDIENTES 4.0: es momento de abordar la documentación relativa a los colegios-seminarios que dependieron del de Badajoz, hoy ya desaparecidos, cuya documentación se custodia en nuestro archivo fundamentado en esta dependencia creada en el entramado organizativo de la estructura de seminarios de la provincia de Badajoz.

Fondo Seminario Menor Elvas-Olivenza 4.01: en la Ciudad de Elvas se estableció un Seminario siguiendo las disposiciones de Trento; se le adjudicaron, para su funcionamiento, diferentes bienes sujetos a la autoridad episcopal diocesana perteneciente al término y jurisdicción de la villa de Olivenza. Por la insuficiencia de sus rentas no pudo subsistir y el obispo, para poder llevar a cabo la instrucción de sus diocesanos, erigió una cátedra de Moral y otra de Instituciones Canónicas en Olivenza.

Censos 4.01.01: como ya señalábamos la economía agraria de España las tierras estaban gravadas por una serie de rentas que se llamaban censos. El Colegio creado en Elvas-Olivenza fue beneficiado por medio de este procedimiento en el siglo XVIII.

Correspondencia 4.01.02: comunicaciones entre el obispado de Badajoz y el Colegio Elvas-Olivenza integran esta serie documental.

Cuentas 4.01.03: documentos puramente contables en la que aparecen los gastos diarios del Colegio desde 1767 a 1868. El análisis de esta documentación nos permitirá confeccionar un diario de a bordo del funcionamiento de una entidad.

Foro de Trigo 4.01.04: documentación contable en el que se estipula el precio del trigo desde 1794 a 1802.

Informes 4.01.05: documentos que desarrollan el funcionamiento de la entidad, así como cuestiones relativas a profesores y alumnos el año de 1799.

Fondo Seminario Menor de Nuestra Señora de la Coronada 4.02: bajo el episcopado del obispo Ramón Rodríguez se compra una casa en la localidad de Villafranca de los Barros para poner en ella el Seminario Menor de que abierto desde 1924 a 1939.

Cuentas 4.02.01: documentos contables en los que aparecen los gastos diarios del Colegio desde 1925-1929. Si tenemos en cuenta el corto periodo de tiempo que la entidad estuvo abierta, la distribución cronológica de la documentación sobre cuentas es ciertamente representativa.

Notas 4.02.02: relación de resultados académicos de los alumnos en el curso de 1929 a 1930.

Fondo Seminario Menor de San Benito 4.03: bajo el episcopado del obispo Fernando Ramírez, se adecúa para Seminario Menor el Palacio de los Priores de Magacela, en Villanueva de la Serena, fundamentalmente, para las vocaciones de esta zona. Funcionó desde 1884 a 1892.

Cuentas 4.03.01: documentos puramente contables en los que aparecen los gastos diarios del Colegio a principios del siglo XIX. 
Escrituras 4.03.02: documentación probatoria que atestigua bienes adscritos a este Colegio-Seminario en 1884.

Matrículas 4.03.03: estos registros de alumnos que cursaron sus estudios en este Colegio son frecuentes en nuestro archivo. La distribución cronológica de la documentación así lo atestigua, permitiendo su estudio desde 1884 a 1891 . El análisis de estos registros nos facilitará el desarrollo de estudios relativos a alumnos, procedencias, edades, cronologías, etc.

Notas 4.03.04: relación de resultados académicos de los alumnos de los cursos 1884 a 1886.

Solicitudes 4.03.05: los alumnos que deseaban ingresar este Colegio-Seminario debían enviar al obispo una súplica o solicitud informando de los deseos que le llevaban a querer ingresar en este centro. En el archivo se conservan solicitudes aisladas del curso 1885-1886.

FONDO MUSICAL 5.0: El fondo musical que integra el archivo del Seminario contiene 90 partituras de música sacra y profana, distribuidas en 17 cajas; complemento a los documentos a papel están las revistas de música.Su estudio enmarcará la promoción musical en muchos de los pueblos de la región, puesto que gran parte los directores de corales adquirieron esta formación en el Seminario.

FONDO COLECCIONES 6.0: el fondo colecciones del Seminario san Atón queda integrado por dos grandes subsecciones que se dedican a la fotografía y a las monedas.

Fotografías 6.01: conjunto de más de 1000 imágenes que describen la vida del Seminario de Badajoz desde el siglo XIX y que son prueba gráfica de la historia de la entidad.

Monedas 6.02: el gabinete numismático de san Atón es sumamente importante, máxime si tenemos en cuenta que la Numismática es como la Archivística, ciencia auxiliar de la historia. Se trata de una colección de más de 5000 monedas desde el siglo III a.C. que está siendo debidamente catalogada y cumplimentada para ser puesta al servicio de la sociedad como documento histórico.

Figura 3. Sección Numismática del Archivo Seminario San Atón de Badajoz
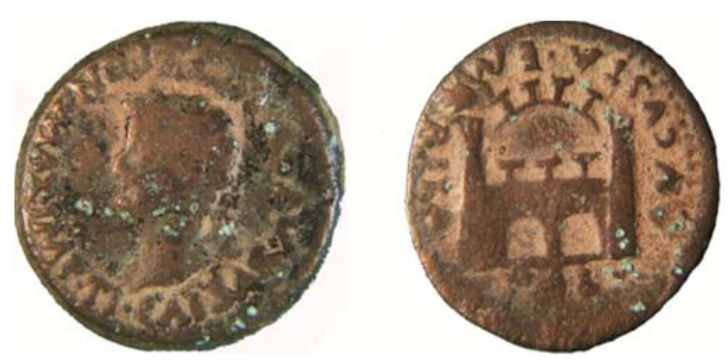


\section{CONTENIDOS HISTÓRICOS EN EL ARCHIVO DEL SEMINARIO METROPOLITANO SAN ATÓN DE BADAJOZ}

Los contenidos que nos facilitan los archivos de seminarios son muy variados. Al igual que ocurre en el caso del Seminario de Badajoz su estudio va a permitir realizar, con base sólida, investigaciones de variada índole. Ahora bien, y centrándonos en el caso particular que nos atañe, debemos destacar los siguientes contenidos:

\section{Educación}

Las series documentales que están intrínsecamente relacionadas con el profesorado y el alumnado nos aportan datos de suma importancia para el conocimiento exhaustivo de tareas educativas.

Estas series, en todos los archivos de seminarios, son fuente de contenidos muy relevantes para la historia, muy concretamente para la educación y especialmente en los siglos XVII-XVIII, puesto que en algunas poblaciones españolas, sirva de ejemplo la ciudad de Badajoz, fueron exclusiva fuente de formación universitaria cuando esta institución aún no había sido concebida. Por ello, sus archivos recogen datos educativos y pedagógicos únicos. No debemos olvidar que en caso pacense el Seminario de San Atón de Badajoz fue sede de la primera Universidad en Extremadura, dependiente de la Universidad de Salamanca, por Real Cédula de Carlos IV, de 17 de agosto de 1793. Este hecho conlleva a la existencia de documentos que dan prueba de un proceso formativo que involucró a personas que en muchos casos no llegaron a ser sacerdotes y utilizaron nuestro Seminario como herramienta de enseñanza universitaria.

Por tanto, estudios sobre la educación y pedagogía en la provincia de Badajoz durante los siglos XVII y XVIII podrán ser fundamentados en base a la documentación custodiada en este archivo. Mediante estos estudios podremos realizar el mapa educativo de la provincia.

\section{Biografías}

Además, y relacionadas con las cuestiones educativas los archivos de seminarios transmiten datos biográficos de sumo interés, recogidos en libros de informaciones y expedientes personales de profesores y alumnos.

En el caso del Seminario de Badajoz, destacan entre otros don Mateo Delgado Moreno, Arzobispo-obispo de Badajoz; don Manuel Godoy, Príncipe de la paz; don José María Calatrava, Presidente del Consejo de Ministros y del Tribunal Supremo; don Fernando Ramírez Vázquez, obispo de Badajoz; don Vicente Barrantes Moreno, ilustre bibliófilo y poeta; don Antonio Senso Lázaro, obispo de Astorga; don José López Prudencio, insigne escritor; don Antonio Reyes Huertas, gran novelista; don Enrique Delgado Gómez, obispo de Pamplona; don Manuel 
Fernández Conde, obispo de Córdoba y don Amadeo Rodríguez Magro, actual obispo de Plasencia.

Sin lugar a duda, los datos que pueden ser extraídos de cada uno de estos personajes en nuestro archivo forman parte de las biografías que sobre muchos de ellos existen ya, y sobre otras que pudieran acometerse en un futuro.

\section{Espiritualidad}

Otra de las cuestiones que puede ser debidamente analizada, según los datos que nos facilitan estos cuadros de clasificación es la relativa a la espiritualidad del momento, dado que el número de expedientes de alumnos por año puede ser considerado como un dato clave en este tema, es decir, los años de más alumnos en los seminarios españoles son entendidos como épocas de mayor esplendor religioso, en detrimento de los años en que el número de vocaciones es menor.

Este hecho se constata nuevamente en nuestro Seminario de Badajoz, siendo el siglo XVII-XVIII el periodo más ampliamente respaldado con un nutrido número de expedientes personales, posteriormente observamos un declive en el número de matriculados que puede estar ocasionado por dos cuestiones: la primera de ellas, el mayor laicismo y la secularización de la sociedady la segunda, es la amplitud de oferta académica en la ciudad de Badajoz.

\section{Artístico/Patrimoniales}

A resaltar también en los seminarios es su patrimonio, debiendo hacer especial hincapié en el artístico. Sus archivos recogen documentación de estas piezas, muchas de ellas sacramentales (cálices, patenas, crucifijos, casullas, manteles bordados, etc), algunas otras artísticas (cuadros y esculturas), otras bibliográficas (libros). En el caso del Seminario de Badajoz haremos especial alusión al patrimonio bibliográfico, dado que hemos localizados legados y catálogos de donaciones de libros de obispos de singular relevancia, sirvan de referencia Solís y Gragera y Soto Mancera.Junto a ello, el enclave geográfico y su estructura arquitectónica (desglosadas en las diferentes obras que se realizaron) favorecerán un estudio funcional del edificio y su finalidad religiosa.

\section{Histórico-Culturales}

Ubicamos en último lugar, no por su menor importancia sino por su heterogeneidad, las cuestiones histórico-culturales. En el marco en el que nos desenvolvemos son muchos y variados, los contenidos relativos a la historia y a la cultura que se ubican en el archivo del Seminario de Badajoz son: planos, sellos, mapas, monedas, medallas, etc. 


\section{CONCLUSIONES}

Remarcar la necesidad inminente de que en todos los archivos que componen la Iglesia católica se efectúen sin más dilación tareas de ordenación, inventariado y clasificación de sus fondos que, no sólo pongan a la luz documentación hasta la fecha inédita, sino que eviten su destrucción, es decir, la lapidación de la historia eclesiástica española. Muy especialmente extrapolamos esta demanda a los archivos de seminarios, dado que son grandes desconocidos dentro del panorama archivístico eclesiástico, a pesar de que contienen una documentación única, la que se refiera a la etapa previa al sacerdocio.

Hemos detectado la escasez de estudios relativos a archivos de seminarios, tanto desde el punto de vista de su organización más general, como del análisis de sus contenidos. Este hecho era de suma importancia en el caso que nos atañe donde existían trabajos previos muy sectoriales y escasamente cotejados con el panorama archivístico actual de nuestro archivo.

El cuadro de clasificación diseñado para el Archivo del Seminario de san Atón de Badajoz debe convertirse en una herramienta útil que puede ser extrapolada, sin lugar a duda, a cualquier otro archivo de seminario dado que su estructura básica recoge fielmente las principales competencias de este tipo de centros: educación y pastoral, tal y como quedan reflejado en las principales secciones y subsecciones que constituyen su cuadro de clasificación documental, permitiendo el establecimiento de patrones básicos aplicables al conjunto de seminarios.

El cuadro de clasificación del archivo del Seminario Metropolitano de San Atón da prueba de un amplísimo entramado de relaciones entre la entidad y multitud de instituciones de las que ha dependido o con las que ha mantenido vínculos a lo largo de sus más de tres siglos de existencia, cuestión que ha dificultado el trazado del cuadro clasificatorio.

El archivo del Seminario Metropolitano de San Atón da cabida a una abundantísima documentación, 140 libros y 131 cajas archivadoras, que es vital para el estudio de cuestiones educativas y pedagógicas. En su archivo hallamos una voluminosa documentación relativa a estas cuestiones, permitiéndonos afirmar que todos aquellos que emprendan estudios relacionados con la educación en Extremadura, desde el siglo XVI al XIX, debieran consultar nuestra documentación para obtener una visión amplia de la situación formativa y pedagógica de Extremadura en dicho periodo. Al acoger el Seminario durante el siglo XVIII la primera Biblioteca pública y el primer centro de enseñanza superior de Badajoz, así como el primer centro universitario de Extremadura se custodian en nuestro archivo documentos vitales para el análisis de estas cuestiones. 


\section{FUENTES ARCHIVÍSTICAS}

\section{FUENTES ARCHIVÍSTICAS. ARCHIVO DEL SEMINARIO SAN ATÓN DE BADAJOZ}

Libro 1 Fundación Seminario (1664-1672)

Caja 1 Reglamento, 1863

Constituciones, 1783

Libro de Constituciones, 1849

\section{BIBLIOGRAFÍA}

ASOCIACIÓN DE ARCHIVEROS DE LA IGLESIA EN ESPAÑA (1997). La Función Pastoral de los Archivos Eclesiásticos. Ciudad del Vaticano: Pontificia Comisión Para los Bienes Culturales de la Iglesia.

BLANCO COTANO, M. (1998). El Primer Centro Universitario de Extremadura: Badajoz, 1793. Historia Pedagógica del Seminario de San Atón.

Cáceres: Universidad de Extremadura.

BROWN, P. (1990). "La Antigüedad Tardía” en ARIÈS P. y DUBY G. (eds.). Historia de la vida privada I. Madrid: Taurus, pp. 230-303.

CONCILIUM Tridentinum, Diariorum, Actorum, Epistularum, Tractatuum nova Collectio IX, 1901, pp. 628-630.

CRISTIANI, L. (1976). El Concilio de Trento. (1518-1534). Fliche y Martin (dir.). Enciclopedia de Historia de la Iglesia. XIX. Valencia: Edicep.

FUENTES NOGALES, C.; PÉREZ ORTIZ, G. (2014), Guía del Archivo del

Seminario Metropolitano San Atón de Badajoz: descripción de sus fondos documentales. Badajoz, 2014.

GARCÍA GARCÍA, A. (dir.) (1990). Synodicon Hispanum. Madrid, BAC.

GARCÍA HERNANDO, J. (1959). El Seminario Conciliar de Segovia: antecedentes históricos. Segovia: Instituto Diego Colmenares.

GONZÁLEZ LOZANO, F.; PÉREZ ORTIZ, G. (2015). "El Archivo del

Seminario Metropolitano San Atón de Badajoz: fuente de datos para el trazado de genealogías de sus alumnos”, en Cuadernos de Genealogía nº16, pp. 9-24.

HERNÁNDEZ CORRALES, A. (1992). El Seminario de la Inmaculada del Archipiélago Canario (1777-1819). Barcelona: Universidad.

HERNANDEZ FIGUEIREDO, J.R. (1992). El Seminario Conciliar de San Fernando de Orense (1804-1952). Roma: Auriae.

MARTÍN HERNÁNDEZ, F. (1959). "Los seminarios españoles en la época de los Borbones”, en Hispania Sacra, no 12, pp. 357-358.

MARTÍNEZ CAMPOS, P.J. (2013). El Seminario diocesano de Almería. Almería: Instituto de Estudios Almeriensis. 
PÉREZ ORTIZ, G; GONZÁLEZ LOZANO, F. (2014). "El archivo del Seminario Metropolitano San Atón de Badajoz: organización de sus fondos documentales", en Ibersid, $\mathrm{n}^{\circ}$ 8, 49-53.

ROPS, D. (1970). Historia de la Iglesia, vol. VII, Madrid, pp. 104-ss.

RUBIO MERINO, P. (1964). El Seminario Conciliar de San Atón. 1664-1964. Madrid.

RUBIO MERINO, P. (1999). Archivística Eclesiástica: Nociones básicas. Sevilla: Guadalquivir.

SÁNCHEZ PASCUA, F. (1985).El Instituto de segunda enseñanza de Badajoz en el siglo XIX (1845-1900). Badajoz: Servicio de publicaciones de la Diputación.

SOLAR Y TABOADA, A. (1945). El Seminario de San Atón de Badajoz (notas históricas). Badajoz.

VIVAS MORENO, A.; GONZÁLEZ LOZANO, F.; PÉREZ ORTIZ, G. (2015). "Sistemas de clasificación en archivos eclesiásticos. El ejemplo de los archivos de Seminarios”, en Ciencias de la Documentación no 1, pp. 105-125. 